I Universidade do Porto, Faculdade de Letras, Porto, Portugal pguerra@letras.up.pt

Paula Guerra'

\title{
UMA CIDADE ENTRE SONHOS DE NÉON. ENCONTROS, TRANSAÇÕES E FRUIÇÕES COM AS CULTURAS MUSICAIS URBANAS CONTEMPORÂNEAS
}

\section{ENTRADA}

Este artigo é parte integrante de um projeto de pesquisa que nos levou a demarcar, a explicar e a interpretar os recortes e as dinâmicas subjacentes à gênese, à constituição e ao funcionamento do subcampo do rock alternativo em Portugal, ao longo dos últimos 40 anos, ${ }^{\mathrm{I}}$ com um enfoque particularizado nas esferas de produção, mediação e procura de bens e obras musicais (Guerra, 20Io, 2013a). Seu foco está na abordagem dos consumos, das relações, das apropriações e das fruições em face da música e correlatas atividades culturais e lúdicas em contexto urbano. São várias as questões centrais decorrentes - quem consome o rock alternativo e o pop rock em geral? De que forma? Consumo, fruição ou apropriação? O consumo musical é acompanhado de outros consumos culturais e lúdicos? Em que contextos? A resposta a essas questões - ou pelo menos a tentativa - resulta na apresentação de nove perfis de fruição musical, cultural e lúdica em I7 espaços de divulgação e de fruição musical, com programação regular nos finais da primeira década deste milênio, situados no Porto e em Lisboa.

O texto organiza-se em torno de lógica narrativa assente em duas seções fundamentais. Inicialmente abordamos os principais desenvolvimentos teóricos relativos ao consumo cultural e musical, num esforço de reatualização da sociologia da cultura contemporânea e sua inevitável ligação com os estudos culturais, a economia criativa, as teorias dos mercados turísticos e lúdicos, e, 
ainda, os estudos urbanos e a história social contemporânea. Em seguida, destacamos as opções metodológicas efetuadas e, após análise geral das práticas de consumo cultural e musical em Portugal nas últimas quatro décadas, expomos uma tipologia de nove perfis compósitos de fruição cultural e lúdica contemporânea nas duas maiores cidades portuguesas: Lisboa e Porto.

\section{AS METAMORFOSES DOS CONSUMOS E FRUIÇÕES CULTURAIS, MUSICAIS E LÚDICAS}

O consumo musical tem sido tema fulcral na sociologia durante as últimas três décadas (DeNora, 2007). Percorridas pelos métodos quantitativos (Bourdieu, 2004, 2007) e qualitativos (DiMaggio, ı987; DeNora, 2000), as investigações - já clássicas - evidenciam o papel da música como um meio de distinção social e de status. Recentemente, a proficuidade das ligações entre gosto, capital cultural e status têm-se mostrado muito relevantes, pelo menos no contexto americano. E qual a razão para esse enfoque? Para DiMaggio (I987), a razão é simples: as artes são a forma cultural de reconhecimento mais prestigiada no mundo ocidental. Em qualquer grupo podem existir formas de conhecimento prestigiantes, que detêm seu valor meramente entre pequenos grupos. O conhecimento artístico assume-se, em geral, como o mais prestigiante e forte indicador de capital cultural. Nessa linha, destacam-se as premissas postuladas por Bourdieu, que deram suporte, nas últimas décadas, a vários estudos empíricos nesse âmbito.

Há que assinalar, não obstante, que autores como Peterson \& Sherkat (I996) e DiMaggio \& Mukhtar (2004) mencionam um declínio da posição da arte como capital cultural, para o qual apontam várias razões: a ubiquidade da cultura popular, que impossibilita que os até então gatekeepers culturais, como universidades e instituições culturais, mantenham sua centralidade cultural (Warde, Martens \& Olsen, I999; Jameson, I99I); a ideia prevalecente de que a alta cultura está desmoronando, resultando em desinstitucionalização (DiMaggio, I987), fruto tanto do multiculturalismo quanto dos próprios artistas, que recusam as barreiras entre cultura popular e "séria"; o fato de atualmente o prestígio cultural decorrer da familiaridade com múltiplas formas artísticas, o que implica a modulação introduzida pelo modelo omnívoro/unívoro (Peterson \& Kern, I996).

De igual modo, não podemos deixar de referir os trabalhos produzidos pelos estudos culturais de Birmingham e suas reatualizações contemporâneas, sobretudo suas contribuições à (re)construção das identidades sociais atribuindo significados às obras musicais e a sua apropriação social numa esfera de volatilidade em substância e espaço (Bennett \& Peterson, 2004). Os trabalhos de Coulangeon (2003 e 20I0) têm contribuído de forma relevante para a análise dos gostos e consumos musicais. Esse autor adianta que alguns comentadores de Bourdieu têm tendência a associá-lo a uma cartografia determinista que faz corresponder o espaço dos gostos ao espaço das posições sociais: "o argumen- 
to da quebra das fronteiras subjacente à metáfora do omnívoro pode não ser radicalmente novo como deixa parecer" (Coulangeon, 20 Io: 89). Ou seja, devemonos perguntar se a hipótese omnívoro/unívoro pode, de fato, implicar um enfraquecimento das hierarquias e das diferenciações culturais, ou se estamos diante de uma reconfiguração das fronteiras e das hierarquias, assumindo a impossibilidade de denegar as diferenciações sociais em torno da música mesmo perante todas as complexidades e perplexidades que nos colocam o hibridismo e o ecletismo cultural-lúdico-artístico-musical contemporâneo. Todas essas investigações têm contribuído para aumentar o patrimônio de saber relativo aos consumos culturais e musicais, mas a flexibilidade continua a ser a pedra de toque por todos enfrentada.

Os trabalhos de Friedman et al. (20I5) e Friedman (20I4) têm sido determinantes a esse respeito, pois consideram que mais importante do que o que se consome é a forma como um bem cultural é apropriado. Se tratará, então, de uma forma de capital cultural emergente? Quatro dimensões assumem particular importância na resposta a essa questão. A primeira se refere aos efeitos geracionais que têm repercussões na relação com o cânone artístico e com uma valorização do "novo" por parte dos mais jovens (Roose, 20I5). A segunda remete ao fato de esse tipo de capital não se associar unicamente a formas "nobres" de arte (Prieur \& Savage, 20I3), evidenciando claramente a importância do capital estético como forma de distinção, em particular aquele derivado da música popular. De acordo com a terceira dimensão, com essa conceitualização, a própria cultura dominante está passando por um longo processo de transformação. E aqui temos de considerar o "abandono" das barreiras nacionais ou europeias, originando formas de capital cultural que valorizam uma visão cosmopolita da cultura (Kuipers, 20I5). A quarta dimensão aponta para a necessidade de um pluralismo metodológico que permita analisar de forma relacional e cruzada os consumos culturais dos agentes sociais e suas modalidades de apropriação (Hennion, I993).

Em Portugal, o estudo das práticas culturais vem sendo objeto de grande investimento, particularmente na década de I990, o que possibilitou uma plataforma de conhecimento e de estratégias de intervenção nesse setor. A música, porém, e as relações e interações que se estabelecem a respeito de seu consumo não têm sido objeto de sistematização tão grande se nos situamos no nível da apropriação quotidiana e nas esferas tradicionais da recepção no que tange ao pop-rock. Se é verdade que "na tradição sociológica a música tem sido frequentemente considerada como um objeto regulador por excelência das lógicas que organizam a esfera da cultura" (Abreu, 2000: I3I), então ainda existe um caminho muito grande a percorrer. Aliás, se a música desempenha hoje papel tão importante na recomposição hierárquica da cultura e na interpenetração dos campos e dos modelos culturais, importa "levantar o véu" do consumo de música popular, numa acepção claramente anglo-saxônica, uma vez 
que ele é exemplar e denominador comum de muitas práticas culturais e de lazer de amplos segmentos da população, especialmente, mas não só, os jovens em todo o mundo. Sem incorrer em exagero, talvez se possa dizer que os consumos de música pop, de forma geral, têm tido papel decisivo no alargamento (relativo) dos grupos sociais com acesso aos bens e serviços culturais e no aumento da cumulatividade e variação dos consumos culturais. E isso acontece porque é nos contextos de interação focalizados na música (concertos, dj sets, live acts) que se intensificam as novas formas de relação entre criador e consumidor facilitadas pelas novas tecnologias (smartphones e demais electronic devices) e a ampliação das indústrias culturais sobretudo quanto à noite, aos festivais e aos eventos lúdicos que - em geral - começam todos pela música. Maria de Lourdes Lima dos Santos (2010: 30) se refere, aliás, a um "consumo pervasivo-cumulativo-fragmentado" a esse respeito - particularmente evidente nos grandes eventos culturais contemporâneos, como o Festival Optimus Alive (Lisboa) ou o Serralves em Festa (Porto).

Notamos dois reveladores dessas transformações: o incremento das "culturas de saídas" entre a população portuguesa. Elas acionam práticas, cenários e perfis sociais específicos que cruzam artes, manifestações culturais e lúdicas que têm pedra de toque na música, mas vão muito além dela. Partilhamos o entendimento de que as "culturas de saídas" funcionam como o segundo ciclo da cultura doméstica: concretizam atividades, significados e espacialidades fulcrais nos processos de sociabilidade juvenil e na disposição de estilos de vida. O outro revelador baliza-se na crescente importância da música "ao vivo" (Bennett, Taylor \& Woodward, 20I4). Para justificar tal ponto de vista, podemos acrescentar que existe atualmente em Portugal, pela primeira vez na história, intensificação da procura e da oferta de música ao vivo no quadro do pop-rock (Guerra, 20I7, 20I6). Se considerarmos que a economia das práticas musicais é complexa e mensurada por meio de ações, cenários e perfis sociais, então ganha peso a questão da fruição musical "em ato" (ao vivo). Ao contrário do que sucede na música clássica, no rock a música nunca foi separada de sua apresentação e de suas cerimônias rituais - objetos de forte investimento por todos os envolvidos. Assistir a um concerto, a um live act ou a uma sessão de djing não significa apenas escutar as músicas; implica antes a demonstração de estilos de vida, de comunidades de sentido, de vivências plurais, de cenas... demonstrando os estrangulamentos do conceito sociológico tradicional de público.

\section{ENCONTROS COM AS CENAS DE CULTURA MUSICAL URBANA}

Focalizando esse entendimento dos consumos culturais e especialmente de música popular na contemporaneidade, situamos nossa análise no cenário dos espaços urbanos de divulgação e fruição musical nas cidades do Porto e de Lisboa. Subjacente a esses espaços, existe a insubordinação em face dos significados absolutos e tradicionais do que são conteúdos e formas culturais, sen- 
do espaços por excelência em que se tornam visíveis alterações nas modalidades tradicionais de canonização cultural e nos habituais sistemas classificatórios de obras e serviços culturais. São espaços liminares (Bennett, Taylor \& Woodward, 20I4) - retirados da esfera rotineira do quotidiano -, que oferecem oportunidades de experimentação de identidades extraordinárias e, em alguns casos, socialmente circunscritas (Guerra, 20I6, 20I7). São figurações de liberdade, em que a identidade e o estilo de vida se fundem e encontram uma articulação coletiva. O que, contudo, não significou o esvaziamento da cultura urbana, muito pelo contrário. Produzida e difundida em ambientes urbanos para audiências locais (Crane, I992), a cultura urbana mostra a convergência atual entre espaço urbano e os art worlds (Becker, I982). A cidade é, portanto, terreno fértil para a fecundação e para a incubação de novas tendências, novos produtos e novos princípios (éthos) culturais.

A escolha desses 17 espaços ${ }^{2}$ deve-se à importância que têm assumido desde o início do milênio no quadro da programação de música pop-rock em Portugal e ainda a sua titularidade enquanto espaços de saída nas duas maiores cidades do país. Fazem parte do roteiro das noites de Lisboa e do Porto e detêm agenda de concertos, dj sets e live acts estabilizada. Assim, o corpus de espaços foi constituído, entre julho de 2006 e julho de 2008, na cidade do Porto por Passos Manuel, ${ }^{3}$ Maus Hábitos, Pitch, Uptown, Contagiarte, Plano B e Porto Rio; e, em Lisboa, por Lounge, ${ }^{4}$ Left, Incógnito, Music Box, Europa, Cabaret Maxime, Mini Mercado, Lux, Zé dos Bois, Frágil e Santiago Alquimista.

Considerando esse quadro, elaboramos o desenho da pesquisa orientado por uma perspectiva de continuum metodológico entre o qualitativo e o quantitativo. Começamos pela aplicação indireta de questionários a uma amostra de 2.I 65 frequentadores de espaços de fruição/divulgação musical/sociabilidades noturnas, I.024 no Porto, e I.I4I em Lisboa. 5 Posteriormente, valorizamos a etnografia, ferramenta heurística em compromisso com o micro, com os sentidos, com o plural, com as diferenças. Nos interstícios dos quotidianos dos espaços, do seu vivido, nas suas múltiplas e invisíveis "artes de fazer" (Certeau, I980) - inspirados por Merleau-Ponty (2004) e, portanto, being-in-the-world - importa ver o mundo que nos é revelado pelos nossos sentidos. Enfim, com a etnografia, entregamos nossos corpos a esses espaços de "música em ato" (Pauwels, 20I5). Continuamente, a realização de entrevistas com frequentadores habituais dos espaços, assim como com seus programadores, gestores ou mesmo proprietários, foi fundamental para esclarecer rituais, validar sentidos e aprofundar esferas de interconhecimento sociológico dos consumos musicais, culturais e artísticos. Em fase subsequente, efetuamos uma análise de correspondências múltiplas, ${ }^{6}$ permitindo, assim, delimitar, identificar, interpretar e esclarecer a estrutura relacional das variáveis intervenientes nos perfis de frequência e de territorialização das práticas de fruição musical, lúdica e cultural do Porto e de Lisboa. 


\section{A CULTURA E A MÚSICA TÊM ROSTOS, IDADES, TERRITÓRIOS E CLASSES}

Quem são os frequentadores dos espaços de fruição e divulgação musical do Porto e de Lisboa? Conde (I997), em seu diagnóstico das práticas culturais em Portugal nos anos I990, contrapunha entre as práticas culturais indoor, domésticas, e outdoor, das "saídas culturais", considerando existir, então, um deficit de práticas fora da esfera dos equipamentos e ações domésticas, fora da privatização e da massificação cultural. O universo das "saídas culturais" era marcado por exiguidade de públicos assíduos e por algumas perdas em certas áreas, sobretudo no teatro e no cinema. No contexto da sociedade portuguesa, e com base nos estudos que incidiam em práticas culturais da década de I990, descortinavam-se três cenários: a massificação introduzida pela cultura midiática e que se fazia sentir especialmente no espaço doméstico; o universo de produções mais especializadas e eruditas, que implicavam uma procura especificamente cultural; e as atividades associadas às indústrias do lazer e do entretenimento. As práticas outdoor que analisamos situam-se neste último cenário, partindo da hipótese de que elas se têm intensificado na última década em Portugal, sobretudo em Lisboa e no Porto (Silva et al., 2000).

No decurso da pesquisa, pudemos identificar de forma direta uma tendência de delineamento da sociografia dos públicos dos espaços de fruição e divulgação musical das cidades do Porto e de Lisboa. Assim, no caso do Porto, verificamos público majoritariamente masculino, proveniente do Grande Porto $(83,1 \%)$ e especificamente dos concelhos do Porto (39,6\%), de Vila Nova de Gaia (I5,I\%) e de Matosinhos (9,7\%). Trata-se de um conjunto de atores sociais cuja maior parte está inserida em agregados familiares de dimensão média, na condição de jovens prestes a iniciar a vida adulta (64,2\% deles trabalham; 29, I\% estudam), muito qualificados (forte presença de estudantes universitários e de licenciados, 33,9\% e 37,2\% respectivamente) e provenientes de classe social elevada: a pequena burguesia intelectual e científica $(\mathrm{PBIC})^{7}(26,4 \%)$ e a pequena burguesia técnica e de enquadramento intermédio (PBTEI) (25,8\%). Do ponto de vista das condições profissionais, predominam, tanto nos participantes quanto em seu contexto familiar, o trabalho para outrem e expressão pouco acentuada de desemprego. Esse retrato dos públicos leva-nos a concluir que estamos diante de um conjunto de agentes sociais em que são visíveis os efeitos geracionais de uma "cultura de saídas", em virtude de sua maior disponibilidade econômica, temporal e etária. Desvela, ainda, os efeitos do processo de massificação escolar, que faz das populações mais jovens na pirâmide etária as mais escolarizadas, e, concomitantemente, melhoria das qualificações profissionais e alguns processos de mobilidade social no sentido ascendente (Silva et al., 2002: I Io). Não obstante a juventude assumir-se como a condição que mais tem atenuado as desigualdades de gênero (Silva, Luvumba \& Bandeira, 2002), trata-se de população ainda majoritariamente masculina, cabendo recordar alguns dos entraves à participação das mulheres no caso do mundo do rock e das saídas com propósi- 
tos de fruição lúdica em torno da música (Davies, 200I; Reddington, 20I2). Essa tendência foi já prefigurada em estudo anterior (Silva et al., 2000) que, quanto às indústrias culturais como o cinema e o disco (cujos indicadores são a compra regular de discos, a frequência a discotecas e bares com ambiente musical), relevava a barreira de gênero, ou seja, a condição de mulher acarreta limitação no caso de práticas vinculadas à saída para o espaço público. Ainda nesse estudo, nota-se que, entre o público portuense, o rock era prática nitidamente juvenil e masculina. Ora, em termos gerais, a estrutura desse público evidencia especificidades juvenis demonstrando a existência de "um peso específico da idade: de um lado, a disponibilidade física e social para o entretenimento no exterior e a maior mobilidade pessoal; do outro, a sucessão de correntes de gosto e a transformação dos padrões de consumo cultural, com uma polarização reforçada na música e no audiovisual" (Silva et al., 2000: 5I). A importância que, de maneira geral, os jovens atribuem à convivialidade pode ser interpretada como signo geracional próprio das culturas juvenis. É em torno das atividades de lazer que a juventude ganha, em certo sentido, especificidade unitária, mas é também a partir dessas atividades que melhor podemos compreender as diferentes culturas juvenis e, a partir dessas, a juventude em sua diversidade (Bennett, 20I I).

\section{PRÁTICAS, TRANSAÇÕES E FRUIÇÕES MUSICAIS, CULTURAIS E LÚDICAS NAS CIDADES}

A frequência dos espaços de divulgação e de fruição musical, tanto no Porto como em Lisboa, sinaliza a presença de um público assíduo. Assim, instados a pronunciar-se sobre seu conhecimento e vinculação ao espaço que frequentavam na ocasião da pesquisa, os diferentes atores sociais revelaram o que podemos chamar de "sentido de fidelidade", mostrando, simultaneamente, a existência de um roteiro definido de cultura musical urbana e uma autoapropriação estável dessas dinâmicas, contrariando visões apocalípticas de circularidade e mobilidade intensa quanto aos espaços e manifestações efêmeras de apropriação musical em espaço urbano. No conjunto daqueles que frequentam os espaços pela primeira vez verificamos, em ambas as cidades, clara predominância da sugestão de amigos como razão para a frequência. No entanto, elas assumem padrões distintos, com a música se revelando mais importante no conjunto de espaços de Lisboa do que nos do Porto. Reportando-nos ao público não novato e às motivações para a frequência dos espaços, reaparecem as dimensões música e sociabilidades, embora a música assuma destaque um pouco maior em ambas as cidades, novamente mais acentuado em Lisboa.

A par com a fidelidade aos espaços em análise, importa uma abordagem mais abrangente do fenômeno social da frequência de espaços de fruição e divulgação musical. Em ambas as cidades, destaca-se a frequência de lugares urbanos de convivialidade e de expressividade lúdica noturna, e, em seguida, dos lugares de lazer e de convivialidade urbanos. Trata-se de preferência de- 
corrente da oferta de bares e/ou discotecas sobretudo em horário noturno, dando ênfase ao que justamente Crane (I992) denominou novos atores urbanos. Essa nomeação é mais acentuada em Lisboa. O que se distingue do Porto, onde atestamos a maior significância dos lugares associativos destinados à expressividade convivial e artística. Assim, esses espaços que funcionam como bares e discotecas decorrem de iniciativas de associações culturais. Demonstra-se, assim, que algumas culturas urbanas são criadas no contexto de redes sociais informais, de criadores e de consumidores que normalmente se conhecem e interagem (Pais, I998) - possuindo, aliás, relações prévias de familiaridade e amizade. As organizações culturais inseridas nessas redes fornecem os recursos para a produção, disseminação e exibição desses trabalhos.

No nível da frequência de espaços e para a perceção de sua abrangência geográfica, podemos identificar circuitos, ainda que distintos, de concentração dessa frequência. É fundamental, no entanto, em termos analíticos, perceber que a variabilidade de padrões geográficos das movimentações dos entrevistados é pouco significativa, demonstrando a prefiguração de uma cena relativamente estável e muito centrada na mancha urbana, diríamos até miolo e baixa, ${ }^{8}$ das cidades em análise. Importa agora debruçarmo-nos sobre as razões para as preferências acima enunciadas, sendo de referir que mais uma vez as dimensões da música e das sociabilidades voltam a sobressair. Em ambas as cidades, a programação dos espaços é indicada como o principal motivo de preferência (mais uma vez mais acentuadamente em Lisboa), seguida dos públicos que frequentam o espaço e de sua visão enquanto potenciador de sociabilidades. Esta análise permite consolidar uma perceção que situa a música e suas diferentes manifestações no cerne das preferências e razões que informam as "saídas" para a noite lisboeta e portuense, dando validade à hipótese de a música ser central em termos de mobilização. A intensa relação entre música e identidade local foi explorada por Cohen (I99I) tendo por base o conceito de cena (Bennett \& Peterson, 2004) enquanto conjunto de atividades sociais em que não existem fronteiras rígidas, mas existem vinculações a espaços específicos de interações. No entendimento de Straw (2005), as cenas, sendo mais frequentemente identificadas as que se relacionam com música, diferenciam-se essencialmente a partir de três fatores: a localização geográfica em que se inserem, a produção cultural e as atividades sociais que as caracterizam. Essas cenas são cruciais porquanto permitem fazer um mapeamento do território urbano, de onde emergem novos usos da cidade, novas relações e interações, e novas semióticas e, por isso, também são essenciais no sentido de que conseguem captar o senso de agitação da cidade e as sociabilidades quotidianas (Guerra, 20I3b). Também Shank (I994) concorda com essa visão mais ampla do conceito de cena, quando refere que pode ser definida como uma comunidade significante de sons, imagens, lifestyles, estéticas, o que resulta numa forma de expressar a teatralidade da cidade ou na capacidade de a cidade gerar imagens das interações. 


\section{PARA UM ENSAIO TIPOLÓGICO DOS PÚBLICOS DAS CENAS DE LISBOA E DO PORTO}

Os gostos musicais têm sido estudados extensivamente como indicadores de fronteiras culturais (e sociais). As indagações acerca dos consumos e gostos musicais têm circulado em torno dos argumentos da homologia de Bourdieu (I979), da individualização (Chan \& Goldthorpe, 2007) e dos consumidores culturais omnívoros e unívoros (Peterson \& Kern, I996; Bryson, I997). Como sabemos, a teoria da homologia é fortemente ancorada na teoria da distinção de Bourdieu que pressupõe o fato de os indivíduos pertencentes a diferentes classes sociais incorporarem diferentes habitus de classe e consequentemente diferentes práticas culturais: "indivíduos que se posicionam em níveis mais elevados da estratificação social tendem a consumir predominantemente a 'alta' cultura ou cultura de 'elite', e indivíduos dos estratos mais baixos são os que preferem e predominantemente consomem a cultura 'popular' ou de 'massas'" (Chan \& Goldthorpe, 2007: I). O argumento da individualização admite que as diferenças nos consumos culturais não estão inter-relacionadas com a estratificação social, mas traduzem uma manifestação pessoal de autorrealização. Contrariando esses dois argumentos, surge outra possibilidade de explicação das práticas culturais: a dualidade omnívoros/unívoros. Diferentemente da proposta bourdieusiana, esse argumento considera que não é possível demarcar limite rígido entre os consumos das classes sociais mais elevadas e sua permeabilidade às massas (Sonnett, 2004). Defende-se, dessa forma, a ideia de que os indivíduos dos estratos sociais mais elevados se caracterizam por omnivoricidade (consumo cultural diversificado e aberto) ou por práticas culturais associadas à cultura de massas - univoricidade (Peterson \& Kern, I996).

Uma das questões mais prementes provindas de um conjunto de estudos levados a cabo nas últimas duas décadas, na França (Coulangeon, 2003, 20I0), permite observar o que poderíamos chamar de crescimento da proporção de "ouvintes omnívoros" entre I 973 e 2008 (Coulangeon, 20 I o: 90). Posto isso, nosso objetivo na abordagem dos frequentadores dos espaços de divulgação e fruição musical foi o de explicar e compreender as práticas culturais urbanas desses agentes sociais, bem como seus gostos musicais, valendo-nos sobretudo dos argumentos da homologia e da dualidade omnívoro/unívoro. Mostramos, assim, que estamos perante um espaço social de consumidores musicais onde se exercem as influências das relações de dominação simbólica - caras a Bourdieu matizadas por contexto crescente de ouvintes cada vez mais omnívoros (Peterson \& Kern, I996; Bryson, I997) em função das alterações da própria estrutura social e das determinações do mercado musical contemporâneo. O chamado cultural turn tem aqui peso importante, consentindo compreender que as questões culturais que afetam os jovens são mais complexas e dinâmicas do que a teoria subcultural considerava serem, quer dizer, as identidades dos jovens passaram a ser vistas e analisadas como identidades reflexivas, que articulam questões especificamente locais com questões globais (Bennett, 20I I). 


\section{Os gostos musicais influenciam a vida}

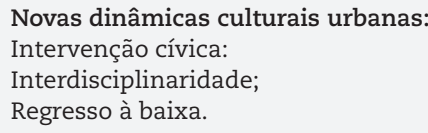

Novas dinâmicas culturais urbanas: Intervenção cívica: Interdisciplinaridade; Regresso à baixa.

reggae

Engajados

Espaços:

Lugares de expessividade artistica e convivialidade

\section{Descomprometidos}

Espaços:

Lugares de lazer

e convivialidade urbanos

jazz, blues

\section{Estabelecidos}

pop rock, indie rock Alternativos

Espaços:

Lugares urbanos de lazer e expessividade artistica

electro tecno, house Sensoriais

\section{Seletivos}

Espaços:

Lugares de performance e representatividade artistica

metal / hard

Resistentes

Espaços:

Lugares públicos de lazer e convivialidade urbanos

\section{Céticos}

Frequência:

Sozinho

\section{Sob influência}

\section{Figura I}

Perfis de fruição musical, síntese das características dominantes

Fonte MUSICULT_2005 | $2009^{9}$ 
Pretendemos, neste momento, mostrar que a estrutura social dos gostos e fruições musicais se prende à heterogeneidade das significações vinculadas à diversidade das experiências e dos contextos de escuta e de fruição musical. Assim, no sentido de analisar, nas páginas que se seguem, os públicos dos espaços de fruição musical e lúdica abordados nas cidades do Porto e Lisboa em 2007 e 2008, recorremos a um processo classificatório que tem em conta um conjunto de fatores escolhidos no âmbito dessa mesma análise que permitiu subdividir o conjunto dos 2.I65 agentes sociais em duas categorias. Na definição do perfil associado englobamos duas linhas de associação do posicionamento dos agentes sociais: a primeira, os espaços frequentados, modula-se de acordo com categorias como cidade, espaços de divulgação e fruição musical, motivos para a frequência do espaço e imagens e estética a ele associadas. A segunda centra-se na sociografia, assente nas variáveis sexo, idade, nível de instrução, pertença de classe e categoria socioprofissional. No entanto, é importante ressalvar que isso só foi possível porque, na atualidade, vivemos um contexto urbano de forte segmentação de objetos musicais e de públicos (musicais). Dessa feita, procurando equacionar da forma mais adequada possível os modos de relação dos agentes sociais com a música, chegamos a nove perfis correspondentes a nove segmentos de públicos frequentadores dos espaços de divulgação e de fruição musical analisados no Porto e em Lisboa, que se apresentam na seguinte tipologia: engajados, descomprometidos, estabelecidos, alternativos, sensoriais, seletivos, resistentes, céticos e sob influência. Na figura I é possível vislumbrar uma síntese dos nove perfis ideal-típicos postulados.

O primeiro perfil, dos engajados, detém 28I indivíduos, o que perfaz I $3 \%$ da amostra, e, em termos de preferências de espaços de divulgação e de fruição musical, assume preponderância nos lugares associativos e destinados à expressividade convivial e artística. Isso nos remete desde já para espaços como o Maus Hábitos e o Contagiarte, que se situam nas novas dinâmicas urbanas de pendor artístico e interdisciplinar e que têm na base um envolvimento as sociativo decorrente da necessidade de um grupo de pessoas intervir na oferta e na agenda culturais da cidade do Porto. Razões significativas que justificam a preferência por esse tipo de espaço são a diversidade funcional, a interdisciplinaridade e a própria componente estética segundo a qual o espaço se estrutura (Hill, 20I7).

Em termos de preferências musicais, os estilos mais significativos, tanto na referenciação de bandas como no autoposicionamento por gênero dos agentes sociais são, em primeiro lugar, o reggae, seguido do folk. Como já visto, esse achado vai ao encontro da própria lógica e do perfil de programação desses espaços. Por exemplo, no caso do Contagiarte, a agenda contempla dias específicos para a apresentação de performances ligadas a esses dois gêneros. $\mathrm{O}$ fenômeno da hibridez dos estilos musicais vem propor um novo ponto de vis- 
ta pelo qual as novas identidades provenientes da música conjugam local e global pela mistura de diferentes tradições musicais na construção de uma identidade local. É nesse sentido que Fortuna \& Silva (2002) consideram que a fusão que caracteriza a world music vem derrubar a possibilidade de um discurso de autenticidade relativo a estilos musicais, sendo também essa a razão de seu crescente estar na moda. Para esses autores há, assim, uma relação entre migração e novas práticas musicais, como reflete a ascensão do turismo musical. Conscientes da relação entre música e lugar, os "pacotes turísticos musicais" tentam dar conta dos estilos de vida locais. Mas a música está também associada à translocalidade no sentido em que o progresso das tecnologias da informação e comunicação veio permitir que a música produzida num dado lugar assuma uma carga simbólica mais vasta, fazendo com que seja crescentemente cool aderir ao reggae ou ao folk.

Ainda nesse perfil, é importante assinalar o posicionamento dos agentes sociais que associam à música uma posição fundamental na estruturação de seu quotidiano, o que vai ao encontro da importância que atribuem à seleção de seus estilos musicais favoritos. Em suma, trata-se de um grupo muito bem definido pelas preferências de espaços e pelos estilos musicais, bem como pelas opiniões bem estruturadas quanto às dinâmicas de cultura urbana, sendo facilmente identificável tanto pela elevada mobilização em torno dos espaços quanto pelo fato de em sua caracterização sociográfica predominar a idade em detrimento da classe social.

O próximo perfil, dos descomprometidos, engloba 207 agentes sociais, compondo Io\% da amostra, que, em termos de preferência de espaços de divulgação e de fruição musical, optam por lugares de lazer e de convivialidade urbana, marcados por descomprometimento quanto à programação musical, valorizando antes a sociabilidade em torno de outros consumos. A razão mais significativa para a preferência desses espaços se prende, aliás, a seus públicos, o que ajuda a caracterizálos como ponto de encontro, etapa preparatória para a noite. A análise das preferências musicais desse grupo de agentes sociais, em termos de estilos, situa-os junto do ska, da música clássica e do trance. Isso nos remete para o fator de transitoriedade, uma vez que esse aparente ecletismo não será fruto de um conjunto de indivíduos ecléticos, mas sim de um conjunto eclético de indivíduos, já que, como pontos de encontro de diversos grupos, esses locais englobam essa pluralidade de gostos dispersada posteriormente por outros espaços na noite. O fato de esses agentes sociais sinalizarem como estilo musical das bandas de referência o pop rock, reforça a ideia que acima apresentamos.

Nesse perfil, o posicionamento dos agentes sociais quanto à influência da música no dia a dia está intimamente relacionado com os estilos de vida que redundam em formas de vestir diferenciadas, em escolhas e na construção de uma identidade. Se a isto associarmos o fato de o grupo etário mais signifi- 
cativo nesse perfil ser o dos I8 aos 22 anos de idade classificados em termos de pertença de classe na PBIC, percebemos claramente que estamos perante um perfil de indivíduos socialmente "privilegiados" dentro da estrutura social portuguesa. Advinda essa pertença do lugar de classe de origem, percebemos aqui também o reforço da transitoriedade, pois a identidade social dos indivíduos não estará ainda sedimentada, o que nos permite concluir que estamos diante de cenário de experiências que levarão à consolidação do self musical. Mercê desse posicionamento, os agentes sociais associam aos espaços de divulgação e de fruição musical frequentados uma estética predominantemente frea $^{\text {I0 }}$ e alternativa ao mesmo tempo que caracterizam a noite como convivial e divertida, familiar e próxima e decadente. Trata-se, portanto, cabe dizer, de um grupo quase exclusivamente definido pela preferência de espaços de lazer e convivialidade urbana, estilos musicais diversos, sem opinião destacada quanto às novas dinâmicas culturais urbanas, com classificações etárias pouco evidentes ainda que com tendência para os mais jovens, não se associando a nenhum espaço de fruição e divulgação musical particular, por isso, o descomprometimento.

O terceiro perfil, dos estabelecidos, aglomera 152 agentes sociais, perfazendo $7 \%$ da amostra, cujas escolhas se voltam para o espaço público urbano, amplo, em frentes marítimas e ribeirinhas ou zonas históricas, e são justificadas pela afinidade/familiaridade que com ele mantêm. Em termos de preferência musical, esse segmento define-se claramente em quatro linhas. As duas primeiras apresentam os valores mais elevados e se situam no jazz e no blues; as outras duas se situam no soul/funk/disco e na música brasileira. Aqui, o perfil tipológico de bandas segue igual tendência, embora não apareça o blues. Em nosso universo de pesquisa, portanto, opção e preferência por determinados nichos em termos de gêneros musicais.

O posicionamento desses agentes sociais em face da representação estética do espaço de fruição/divulgação musical/sociabilidade frequentado, destaca o conceito de glamour como mais relevante. ${ }^{\text {II }}$ Nessa medida, se combinarmos o que temos dito a respeito desse perfil com as categorias associadas em termos sociográficos, identificamos a pertença predominante nesse segmento de agentes sociais com mais de 37 anos que exercem atividade profissional, aspecto, aliás, que influencia seu gosto musical: a música aparece intimamente ligada à atividade profissional desses agentes. Sob esse ponto de vista, está também presente uma noção de que as novas dinâmicas de cultura urbana apostam na mistura de estilos e de gostos situando-as no interior dos limites da cidade, indo ao encontro dos posicionamentos. Finalmente, é importante relevar que sua descrição da noite assenta nas categorias de convivial e divertida, bem como de arte e cultura. Em síntese, três modelações especificam esse grupo. A primeira aponta para preferências musicais, com destaque para o jazz e o blues; a segunda aponta para preferência por espaços em que a fami- 
liaridade e a afinidade (roupas, estilos e modos de estar) são importantes. A terceira prende-se ao fato de estarmos perante um grupo que oscila entre os 37 e os 40 anos de idade e que detém alguma atividade profissional.

O quarto perfil, dos alternativos, é constituído por 67 I indivíduos, representando 3I\% da amostra, que assumem a preferência por lugares urbanos de convivialidade (Europa e Incógnito) e de expressividade lúdica noturna (Left e Lounge), situados predominantemente em Lisboa. No âmbito dos espaços de fruição/divulgação musical/sociabilidades, há que relevar dois aspectos. Por um lado, a existência de dois espaços, sendo um muito recente, o Europa, que abre em 2008 e ganha notoriedade pelas after-hours, e outro mais antigo, com mais de duas décadas, o Incógnito, que se mantém como um baluarte do indie rock e do rock alternativo, tendo grau de fidelização muito elevado. Por outro lado, também surgem associados a esse perfil, o Left e o Lounge, o primeiro claramente concebido para a divulgação de dj sets/live acts de nomes associados ao indie e electro, e marcado por muita intermitência em termos de funcionamento, e o segundo, aberto todos os dias da semana, com relevante programação no que concerne ao rock alternativo e a sonoridades emergentes, fruto do programador específico, e que, apesar de sua dimensão reduzida, acaba por cunhar os principais marcos programáticos do rock alternativo em Lisboa e funciona cada vez mais como antecâmara da discoteca (normalmente Incógnito ou Lux).

Para esse segmento, a programação, seguida pela componente estética, é a razão fundamental para a escolha do espaço (Fortuna, 2002). Em termos de frequência, esses indivíduos fazem-na acompanhados de amigos/as. Em termos de estilos musicais preferidos é enorme o relevo dado ao alternativo/indie rock e ao pop/rock, o que redunda na escolha de bandas que apresentam esse espectro musical.

Ainda nesse perfil, há algo de extrema importância a ressalvar. Para todos esses agentes sociais, e assinale-se essa unanimidade, os gostos musicais influenciam a vida por meio principalmente dos estados de espírito, dos estilos de vida, da banda sonora do eu (DeNora, 2000) e dos lazeres e convivialidades. No que concerne aos posicionamentos acerca da noite, esse grupo a situa em dois casos: aberta e cosmopolita ou diversa e polivalente. Temos também aqui uma diferenciação sobredeterminada por idade, sexo e escolaridade. Destacase o sexo feminino, os indivíduos com pós-graduação e o intervalo dos 3 I aos 36 anos. Em síntese, encontramos aqui um grupo muito bem definido pelos espaços de fruição/divulgação musical/sociabilidades e pelos estilos musicais, com opiniões bem notórias quanto à influência da música na vida quotidiana, muito associados a espaços situados em Lisboa e de cujo perfil sociográfico consta a presença de muitos indivíduos do sexo feminino. É também o perfil que mais se aproxima do subcampo do rock alternativo em Portugal.

O quinto segmento, dos sensoriais, compõe-se por 207 agentes sociais que representam Io\% da amostra. A exemplo do anterior, esse perfil também 
assume como espaços de fruição/divulgação musical/sociabilidades preferidos os lugares urbanos de convivialidade e de expressividade lúdica noturna dos quais se destacam o Mini Mercado e o Lounge. Suas motivações para a frequência desses espaços se devem à realização de eventos musicais, associando-lhes imagem ligada ao design e ao décor. Em termos de estilos musicais, aos quais as bandas também estão relacionadas, há um núcleo importante que se alicerça na música de dança, nomeadamente nos gêneros electro, techno e house. Também a exemplo do perfil anterior, encontra-se nos sensoriais forte ligação entre os gostos musicais e a vida, sobretudo porque identificam a música como elemento fundamental da influência sobre os estados de espírito. Por outro lado, observamos nesse perfil, e ao contrário do que vimos nos anteriores, identificação às novas dinâmicas urbanas na periferia, o que pode advir de duas razões. A primeira prende-se ao fato de estarmos tratando de uma realidade sobretudo lisboeta, cujos movimentos quotidianos são marcados pela pendularidade. A segunda relaciona-se com a percepção, partilhada por músicos e produtores, de que a periferia lisboeta, dada a presença multicultural, abriga dinâmicas emergentes do hip-hop, do kuduro e da eletrônica.

Outro ponto a assinalar diz respeito às imagens associadas à noite por esses agentes sociais em que, pela primeira vez, emerge o eixo "álcool, drogas e excessos" a par dos eixos "fashion e glamour" e "decadente". Em termos sociográficos encontramos aqui indivíduos que não trabalham ou estudam, situados entre os 23 e os 26 anos. Esse perfil salienta as preferências musicais dos indivíduos pelo electro, o que pode indiciar um grupo no qual a presença de tendências ligadas a uma mescla de eletrônica minimal com sonoridade próxima do indie mais alternativo o aproxima do grupo anterior em termos de fruição musical.

Os 79 agentes sociais do sexto perfil analisado, o dos seletivos, constituem $4 \%$ da amostra. Esse perfil é minoritário e marcado particularmente pela procura específica de espaços de acordo com sua oferta e associados à performatividade artística como elemento que distingue esse grupo a par da grande heterogeneidade que podemos inferir dos elementos apresentados, que não se enquadram de forma alicerçada em nenhuma das categorias do perfil. Destacam-se o Porto Rio e, num segundo plano, a Galeria Zé dos Bois e o Santiago Alquimista e, concomitantemente, a maior prevalência de gêneros musicais ligados ao jazz, à música brasileira e ao drum'n'bass, bem como a representação da importância da música como profissão e ainda a perceção da noite ligada a drogas, álcool e excessos.

O sétimo perfil, dos 152 resistentes, representa $7 \%$ da amostra, e nele importa assinalar a frequência de espaços como o Music Box, o Santiago Alquimista e o Uptown. No nível da imagética do espaço, os agentes sociais avançam com uma caracterização de "industrial" a que associam um sentimento de agradabilidade. Levando em conta o tipo de espaços de fruição/divulgação musical/ 
sociabilidades preferidos, no entanto, eles se ligam à categoria de espaços públicos de lazer e convivialidade por razões relacionadas com a potenciação de sociabilidades. Nesse perfil é interessante observar o significado de estilos musicais situados primeiramente no metal/hard e subsequentemente no dark/ goth/industrial, bem como a enunciação vincada de bandas metal/hard. Ainda no segmento da música, esses agentes sociais a consideram importante em sua vida porque funciona como banda sonora do eu (DeNora, 2000). Em face das novas dinâmicas culturais urbanas, apresentam posicionamento extremamente marcado, situando essas dinâmicas na periferia, distanciando-as do regresso à baixa ${ }^{\mathrm{I} 2}$ enquanto modo de vida, dos espaços de lazer interdisciplinares e intervenção cívica e cultural associada ao lazer, categorias essas a que atribuem a qualidade de afirmações falsas.

É também muito significativo não só enquanto categoria, mas partindo de uma visão totalizadora do conjunto dos perfis, a associação da noite a um contexto elitista e fechado. Cabe observar que esse é o único perfil em que encontramos como muitíssimo significativa a pertença a franjas do operariado, o gênero masculino e escolaridade delimitada ao ensino secundário. Em suma, trata-se de perfil bem individualizado, ligado ao tipo de espaços que frequentam e às razões de frequência, assim como às preferências musicais, e com opiniões gerais bem marcadas e opostas, por exemplo, às do primeiro grupo, além de possuir características sociográficas bem definidas.

No oitavo perfil, dos céticos, com 79 indivíduos que refletem $4 \%$ da amostra, encontramos indivíduos que frequentam, sozinhos, o Incógnito e o Porto Rio porque preferem espaços que sejam lugares urbanos de convivialidade de expressividade lúdica noturna. Assim, não é de estranhar que apresentem como motivos para a frequência do espaço, em pé de igualdade, eventos musicais, consumos e convivialidade e que avaliem a noite como monótona e repetitiva, limitada e pequena.

Em termos de imagens associadas aos espaços frequentados, aparecem como importantes a familiaridade e os amigos situados numa estética underground. Esses indivíduos são, de forma mais significativa, homens com mais de 40 anos, aos quais não é possível associar gêneros musicais, apesar de apontarem a música como algo que os influencia no dia a dia por meio da banda sonora do eu (DeNora, 2000). Quanto às novas dinâmicas de cultura urbana, associam-na à periferia e avaliam como falso o regresso à baixa enquanto modo de vida, apostando na mistura de estilos e de gostos. Condensando, temos um grupo sem preferências musicais distintivas que se destaca pelo tipo de frequência dos espaços, marcado por faixa etária mais elevada. Trata-se de um grupo assinalado pela frequência de espaços próximos e nos quais as redes de interconhecimento são muito relevantes.

O nono perfil, dos sob influência, destaca-se de todos os anteriores, posto que os gostos musicais não influenciam a vida para as 316 pessoas - I $5 \%$ da 
amostra - que o constituem. Podemos encontrar esses indivíduos, que têm entre 27 e 30 anos e trabalham, em espaços como o Plano B, porque preferem lugares de lazer e de convivialidade urbanos que frequentam com o/a companheiro/a. Em termos de estilos musicais, sejam bandas ou estilos favoritos, aparece como mais significativo o pop rock. Em termos de imagens associadas à noite são significativas a familiaridade e a proximidade.

Quanto ao posicionamento em face das novas dinâmicas de cultura urbana, negam que estejam associadas a intervenções cívicas e culturais relacionadas com o lazer, assim como, embora em menor grau, que sejam marcadas pela efemeridade. Em síntese, encontramos nesse grupo o outlier de nossa análise, uma vez que se individualiza por considerar que os gostos musicais não influenciam a vida, surgem sobretudo na modalidade de acompanhantes da frequência dos espaços, portanto seu deslocamento ocorre sob influência de amigos/as, namorado/a e companheiro/a.

\section{CONCLUSÃO: DE VOLTA À ANACRUSE OU TUDO MISTURADO OUTRA VEZ}

É para nós, indiscutível, o sentido propedêutico, mas simultaneamente inacabado desta investigação. Os resultados alcançados não se esgotaram e abriram caminho a novas pesquisas (Guerra \& Silva, 20I5; Silva \& Guerra, 2015, entre outros), que contribuíram para reforçar o caráter fugidio de nosso objeto, ins crito num real sempre infinito.

Uma das primeiras proposições que aprofundamos no desenvolvimento da pesquisa centrou-se na defesa de uma sociologia cultural da música menos determinista, de acordo com a qual a relação da estrutura social com as escolhas e as práticas musicais implica um processo dinâmico quotidiano de "recepção, apropriação e estetização dos textos da música popular, dos artefatos e recursos associados que são integrais à produção de significado musical" (Bennett, 2008: 430). Tal direção não se funda na irrelevância das determinantes inerentes à estrutura social, mas no reconhecimento, no quadro de devir constante, de plurais e diversas modalidades de (in)determinação da prática e do consumo musical no escopo do rock enquanto universo simbólico-ideológico e espaço de inter(ações).

Outra possível afirmação decorrente deste trabalho prende-se à ressalva da visibilidade da abordagem sociológica no enriquecimento da perspetiva musicológica, posto que a primeira situa o fato musical tanto em suas ligações com o passado quanto nas complexas imbricações com o presente. Assim, defendemos uma abordagem compreensiva que pressupõe o interesse pela perspectiva dos agentes sociais, pelas relações de sentido que eles têm com o musical, pois compreender é apreender as ações sociais no contexto da experiência quotidiana do musical. A ambição última foi, assim, considerar que os fatos musicais são, simultaneamente, produtores e receptores de transformações sociais, porquanto "mundos da arte" acolhem e exteriorizam normas e conven- 
ções sociais, fazem parte da dinâmica mais profunda que dá corpo e ser a todos os objetos artísticos, por mais que seja eternizado um discurso de senso comum contrário a esse posicionamento.

Assim sendo, reportando-nos aos resultados obtidos, consideramos ser particularmente relevante o enquadramento desses atores sociais numa esfera de cosmopolitismo estético e lúdico ou capital cultural cosmopolita (Friedman et al., 20I5), isto é, um saber-fazer e saber-estar na experimentação e fruição da diferença cultural, por meio do consumo e de práticas culturais urbanas. Foi, aliás, isso que nos ensinou Regev (2013) quanto ao pop-rock. De igual modo relevante é a contínua importância estruturadora da música no nível das diversas práticas culturais urbanas. Apesar de não ser o único fator encontrado em nosso estudo, e não podendo deixar de mencionar a importância das dinâmicas de sociabilidade, consideramos que a música serve como engodo para outras práticas, bem como um potenciador essencial para a compreensão das novas formas de cosmopolitismo estético e lúdico que encontramos nos jovens (e não só) portugueses.

Não gostaríamos de fechar este artigo sem fazer alusão à diversidade de perfis de fruição cultural, lúdica e musical presentes nas cidades. Mas paradoxalmente também a sua homogeneidade. Ora, se afirmamos com Machado Pais (20I0: I66) que "a cultura hegemônica é bem mais uma cultura de exclusão do que inclusão", onde estão espacializadas e inscritas as manifestações culturais, lúdicas e musicais das restantes classes sociais? Certamente invisíveis e fora dos centros das grandes cidades portuguesas em não lugares, em periferias, em espaços segregados social e territorialmente.

Recebido em 3I/I/20I8 | Revisto em 24/5/2018 | Aprovado em 30/5/2018

Paula Guerra é professora da Faculdade de Letras da Universidade do Porto (FLUP) e pesquisadora do Instituto de Sociologia da Universidade do Porto (IS-UP). Investigadora colaboradora no Centro de Estudos Geográficos e Ordenamento do Território (CEGOT) e no Centro de Investigação Transdisciplinar Cultura, Espaço e Memória (CITCEM). É professora adjunta no Griffith Centre for Cultural Research (GCCR). 


\section{NOTAS}

I O trabalho de campo - entrevistas, observações etnográficas, aplicação de questionários - foi realizado entre 2004 e 2009. O arco analítico do projeto, todavia, tem por base a abordagem do rock como prática social enquanto produção e reprodução societal no âmbito da sociedade contemporânea, designadamente na sociedade portuguesa entre I980 e 20 IO.

2 Originalmente seriam I8, mas não foi possível aplicar o questionário no Lux, em Lisboa, uma vez que é política do espaço garantir a intimidade e o anonimato de seus clientes.

3 Cf. https://oportocool.wordpress.com/.

4 Cf. http://www.agendalx.pt/.

5 Na elaboração da amostra, consideramos a população residente na Grande Área Metropolitana do Porto (GAMP), que totalizava, segundo os dados disponíveis em 2007 , 608.463 indivíduos, e, no caso da Grande Área Metropolitana de Lisboa (GAML), 98I.2I7 indivíduos. Atualmente (20I7), a GAMP conta com I7 municípios, que perfazem mais de I.500.000 habitantes. A GAML, situada no centrosul português, é constituída por 18 municípios e é a área metropolitana mais populosa de Portugal.

6 A tipologia de públicos quanto às preferências de fruição musical foi realizada com base na aplicação de uma análise de correspondências múltiplas, uma classificação mista (de centros móveis e hierárquica), e uma descrição dos grupos classificados (segundo o grau de representação de cada modalidade de resposta no conjunto dos indivíduos de cada grupo), sobre o conjunto das respostas dos 2.I65 indivíduos. A dimensão amostral e a equilibrada distribuição dos inquéritos nos vários espaços garantem as condições de base necessárias para um bom grau de confiança nos resultados. As questões selecionadas para a definição dos perfis da tipologia referem-se às opiniões e preferências de caráter geral dos envolvidos - influência da música no quotidiano, preferências musicais, posicionamento quanto às novas dinâmicas culturais urbanas, tipo de espaços preferidos para fruição musical, motivos e situação preferidos para frequência dos espaços, opinião quanto à noite de Lisboa ou do Porto. Os perfis identifica- 
dos foram complementados com perfis associados, que ilustram as principais características dos grupos com relação às opiniões que revelam sobre o espaço em que foram entrevistados - localização, imagem, estética, programação musical, razões de frequência, conhecimento do espaço e características sociodemográficas mais representativas dos participantes.

7 Recorremos à tipologia classificatória das classes e frações de classes desenvolvida por Magalhães (2005).

8 Por "baixa" referimo-nos a um perímetro histórica e urbanisticamente definido nessas duas cidades (Peixoto, 2003). A baixa de Lisboa, ou baixa pombalina, totalmente reconstruída após o terremoto de 1755 , estende-se das margens do rio Tejo até a avenida da Liberdade e está situada entre as colinas das áreas de Alfama e Chiado. A baixa do Porto engloba os principais pontos da cidade: avenida dos Aliados, rua de Santa Catarina, estação ferroviária de São Bento, o mercado do Bolhão, entre outros.

9 Foram identificados nove perfis-tipo de públicos, cuja síntese genérica e posição relativa estão representadas nessa figura. A leitura das características de cada perfil é fundamental para compreender a tipologia, o que, como é natural, não significa necessariamente que todos os indivíduos de cada perfil apresentem literalmente todas as características descritas como significativas. A tipologia evidencia os fatores comuns que surgem sobrerepresentados em cada grupo de indivíduos. Na generalidade, os grupos são bem definidos, correspondem a opiniões e a motivações distintas de fruição, havendo, como é evidente, alguns perfis nucleares (A, D, G) e outros que evidenciam situações mais específicas.

Io Considerando a proximidade às referências, representações e palavras dos entrevistados, freak é uma expressão associada ao movimento hippie na generalidade.

I I Considerando a proximidade às referências, representações e palavras dos entrevistados, o conceito de glamour remete para um cosmopolitismo estético, não só associado à moda, mas também em termos de decoração, de arquitetura, de atmosferas.

I2 Esse regresso à baixa é fenômeno mais recente, do início do milênio, e tem caráter lúdico, visando usufruir dos la- 
zeres locais. Dada, porém, a crescente especulação imobiliária e fundiária, bem como os processos de gentrificação e turistificação, isso implicou a saída de uma parte da população, nomeadamente das franjas das classes médias urbanas baixas e populares (Peixoto, 2003; Mendes, 20I4).

\section{REFERÊNCIAS BIBLIOGRÁFICAS}

Abreu, Paula. (2000). Práticas e consumos de música(s): ilustrações sobre alguns novos contextos de prática cultural. Revista Crítica de Ciências Sociais, 56, p. I23-I45.

Becker, Howard S. (I982). Art worlds. London: University of California Press.

Bennett, Andy. (20II). The continuing importance of the 'cultural' in the study of youth. Youth Studies Australia, 30/3, p. 27-33.

Bennett, Andy. (2008). Towards a cultural sociology of popular music. Journal of Sociology, 44/4, p. 4I9-432.

Bennett, Andy \& Peterson, Richard A. (2004). Music scenes: local, translocal and virtual. Nashville: Vanderbilt University Press.

Bennett, Andy; Taylor, Jodie \& Woodward, Ian (orgs.). (2014). The Festivalization of Culture. London/New York: Routledge.

Bourdieu, Pierre. (2007). A distinção: crítica social do julgamento. São Paulo: Editora Zouk.

Bourdieu, Pierre. (2004). Questões de sociologia. Lisboa: Fim de Século.

Bourdieu, Pierre. (1979). Les trois étapes du capital culturel. Actes de la Recherche en Sciences Sociales, 30/I, p. 3-6.

Bryson, Bethany. (I997). What about the Univores? Musical dislikes and group-based identity construction among Americans with low levels of education. Poetics, 25, p. I4I-I56.

Certeau, Michel de. (I980). L'invention du quotidien. Paris: Union Générale d'Editions (Arts de faire I).

Chan, Tak Wing \& Goldthorpe, John H. (2007). Social stratification and cultural consumption: music in England. European Sociological Review, 23/I, p. I-I9. 
Cohen, Sara. (I99I). Rock culture in Liverpool: popular music in the making. New York: Oxford University Press.

Conde, Idalina. (1997). Cenários de práticas culturais em Portugal (I979-I995). Sociologia - Problemas e Práticas, 23, p. I I7-I88.

Coulangeon, Philippe. (2010). Les métamorphoses de la légitimité. Classes sociales et goût musical en France, I973-2008. Actes de la Recherche en Sciences Sociales, I8I-I82, p. 89-105.

Coulangeon, Philippe. (2003). La stratification sociale des gouts musicaux: le modèle de la légitimité culturelle en question. Revue Française de Sociologie, 44/I, p. 3-33.

Crane, Diana. (I992). The production of culture - media and the urban arts. London: Sage.

Davies, Helen. (200I). All rock and roll is homosocial: the representation of women in the British rock music press. Popular Music, 20/3, p. 30I-319.

DeNora, Tia. (2007). Consumption of Music. In: The Blackwell Encyclopedia of Sociology. Hoboken/New Jersey: Blackwell Publishing.

DeNora, Tia. (2000). Music in everyday life. Cambridge: Cambridge University Press.

DiMaggio, Paul. (1987). Classification in art. American Sociological Review, 52, p. 440-455.

DiMaggio, Paul \& Mukhtar, Toquir. (2004). Arts participation as cultural capital in the United States, 1982-2002: signs of decline? Poetics, 32/2, p. I69-I94.

Fortuna, Carlos. (2002). Culturas urbanas e espaços públicos: sobre as cidades e a emergência de um novo paradigma sociológico. Revista Crítica de Ciências Sociais, 63, p. I23-I 48 .

Fortuna, Carlos \& Silva, Augusto Santos. (2002). A cidade do lado da cultura: espacialidades sociais e modalidades de intermediação cultural. In: Santos, Boaventura de Souza (org.). A globalização e as ciências sociais. São Paulo: Cortez.

Friedman, Sam. (2014). Comedy and distinction: the cultural currency of a "Good" sense of humour. London/New York: Routledge. 
Friedman, Sam et al. (2015). Cultural sociology and new forms of distinction. Poetics, 53. p. I-8.

Guerra, Paula. (2017). A revolução do festival: um percurso pela agenda dos festivais pop rock portugueses na última década. In: Pires, Victor \& Almeida, Laís (orgs.). Circuitos urbanos, palcos midiáticos: perspectivas culturais da música ao vivo. Maceió: Edufal, p. 29-53.

Guerra, Paula. (2016). From the night and the light, all festivals are golden": the festivalization of culture in the late modernity. In: Guerra, Paula \& Costa, Pedro (orgs.). Redefining art worlds in the late modernity. Porto: Universidade do Porto, p. 39-67.

Guerra, Paula. (2013a). A instável leveza do rock: génese, dinâmica e consolidação do rock alternativo em Portugal (I980-20I0). Porto: Afrontamento.

Guerra, Paula. (2013b). Punk, ação e contradição em Portugal. Uma aproximação às culturas juvenis contemporâneas. Revista Crítica de Ciências Sociais, I02-I03, p. III-I34.

Guerra, Paula. (2010). A instável leveza do rock: génese, dinâmica e consolidação do rock alternativo em Portugal (I980-2010). Dissertação de Doutoramento em Sociologia. Faculdade de Letras/Universidade do Porto.

Guerra, Paula \& Silva, Augusto Santos. (2015). Music and more than music: the approach to difference and identity in the Portuguese punk. European Journal of Cultural Studies, I8/2, p. 207-223.

Hennion, Antoine. (1993). La passion musicale. Une sociologie de la médiation. Paris: Édition Métailié.

Hill, Wes. (20I7). Art after the Hipster. Identity politics, ethics and aesthetics. Basingstoke: Palgrave Macmillan.

Jameson, Fredric. (I99I). Postmodernism or the cultural logic of the late capitalism. London: Verso.

Kuipers, Giselinde. (20I5). Beauty and distinction? The evaluation of appearance and cultural capital in five European countries. Poetics, 53, p. 38-5I.

Magalhães, Dulce. (2005). Dimensão simbólica de uma prática social: consumo do vinho em quotidianos portuenses. Tese de Doutoramento em Sociologia. Faculdade de Letras/Universidade do Porto. 
Mendes, Luís. (20I4). Gentrificação e políticas de reabilitação urbana em Portugal: uma análise crítica à luz da tese rent gap de Neil Smith. Cadernos Metrópole, 16/32, p. 487-5II.

Merleau-Ponty, Maurice. (2004). The world of perception. London: Routledge.

Pais, José Machado. (20I0). Lufa-lufa quotidiana. Ensaios sobre a cidade, cultura e vida urbana. Lisboa: Imprensa de Ciências Sociais.

Pais, José Machado. (I998). As 'cronotopias' das práticas culturais do quotidiano. OBS, 4, p. 7-9.

Pauwels, Luc. (20I5). 'Participatory' visual research revisited: a critical-constructive assessment of epistemological, methodological and social activist tenets. Ethnography, I6/I, p. 95-II7.

Peixoto, Paulo. (2003). Centros históricos e sustentabilidade cultural das cidades. Sociologia: Revista da Faculdade de Letras da Universidade do Porto, I3, p. 2II-226.

Peterson, Richard A. \& Kern, Roger M. (I996). Changing highbrow taste: from snob to omnivore. American Sociological Review, 5/6I, p. 900-907.

Peterson, Richard A. \& Sherkat, Darren E. (I996). Age factors in arts participation: I982-I992. Washington DC: National Endowment for the Arts.

Prieur, Annick \& Savage, Mike. (2013). Emerging forms of cultural capital. European Societies, I5/2, p. 246-267.

Reddington, Helen. (2012). The lost women of rock music. Sheffield: Equinox.

Regev, Motti. (2013). Pop-rock Music. Aesthetic cosmopolitanism in late modernity. Cambridge: Polity Press.

Roose, Henk. (2015). Signs of 'emerging' cultural capital? analysing symbolic struggles using class specific analysis. Sociology, 49/3, p. 556-573.

Santos, Maria de Lourdes Lima dos. (2010) Uma panorâmica com três vertentes e duas dimensões. In: Santos, Maria de Lourdes Lima dos \& Pais, José Machado (orgs.). Novos trilhos culturais. Práticas e políticas. Lisboa: Imprensa de Ciências Sociais, p. 29-35. 
Shank, Barry. (1994). Dissonant Identities: The rock'n'roll scene in Austin, Texas. Hanover: Wesleyan University Press. Silva, Augusto Santos \& Guerra, Paula. (2015). As palauras do punk. Lisboa: Alêtheia.

Silva, Augusto Santos et al. (2000). Públicos para a cultura, na cidade do Porto. Porto: Edições Afrontamento/Câmara Municipal do Porto.

Silva, Augusto Santos et al. (2002). As práticas e os gostos: uma sondagem do lado das procuras de cultura e lazer. In: Projecto e circunstância: culturas urbanas em Portugal. Porto: Edições Afrontamento, p. Io9-I62.

Silva, Augusto Santos; Luvumba, Felícia \& Bandeira, Graça. (2002). A arte de ser culto: a formação e as práticas dos consumidores regulares. In: Projecto e circunstância: culturas urbanas em Portugal. Porto: Edições Afrontamento, p. I63-2Io.

Sonnett, John. (2004). Musical boundaries: intersections of form and content. Poetics, 32, p. 247-264.

Straw, Will. (2005). Cultural Scenes. Loisir et Société/Society and Leisure, 27/2, p. 4II-422.

Warde, Alan; Martens, Lydia \& Olsen, Wendy. (I999). Consumption, the problem of variety cultural omnivorousness. Social distinction, dining out. Sociology, 33, p. I05I 27. 
UMA CIDADE ENTRE SONHOS DE NÉON. ENCONTROS, TRANSAÇÕES E FRUIÇÕES COM AS CULTURAS MUSICAIS URBANAS CONTEMPORÂNEAS

\section{Resumo}

O artigo decorre do desenvolvimento teórico-empírico de um projeto de doutoramento sobre as culturas urbanas e as cenas musicais contemporâneas portuguesas, que demarcou e interpretou as dinâmicas subjacentes à gênese, à constituição e ao funcionamento do subcampo do rock alternativo em Portugal ao longo dos últimos 40 anos. Enfoca especificamente os perfis de fruição cultural, artística e musical das cidades do Porto e de Lisboa na última década, observando tendências, dissemelhanças, perseveranças e especificidades. $O$ estudo constata a emergência de uma juventude portuguesa enquadrada na esfera do cosmopolitismo estético e lúdico, detentora de um capital cultural cosmopolita - isto é, de um saber-fazer e saber-estar na experimentação e fruição da diferença cultural, por consumo e práticas musicais, artísticas e culturais urbanas marcadas pelo hibridismo e o ecletismo.

\section{A CITY BETWEEN NEON DREAMS. ENCOUNTERS, TRANSACTIONS AND ENJOYMENTS IN URBAN MUSICAL CULTURES}

This article derives from the theoretical and empirical development of the author's doctoral research on urban cultures and contemporary Portuguese music scenes, which sought to demarcate and interpret the dynamics underlying the genesis, constitution and functioning of the subfield of alternative rock in Portugal over the last 40 years. It focuses specifically on the cultural, artistic and musical fruition of the cities of Oporto and Lisbon over the last decade, observing dissimilarities, persistences and specificities. This study confirmed the emergence of a Portuguese youth framed in the sphere of aesthetic and playful cosmopolitanism, bearer of a cosmopolitan cultural capital - that is, a savoir-faire and savoir-viure in the experimentation and enjoyment of cultural difference, through consumption and urban musical, artistic and cultural practices marked by hybridity and eclecticism.

\section{Palavras-chave}

Procura cultural;

culturas urbanas; música alternativa; fruição cultural e lúdica; públicos da cultura.

Keywords

Cultural demand; urban cultures; alternative music; cultural and ludic fruition; cultural audiences. 